\title{
The Art and Science of the Glacial Lake Clays of the Sugar Creek Valley, Bradford County, Pennsylvania
}

Aaron Bierly, DCNR-Pennsylvania Geological Survey, aabierly@pa.gov and Roger Pollok, P.G., sculptor and consulting geologist, nittanywps@aol.com

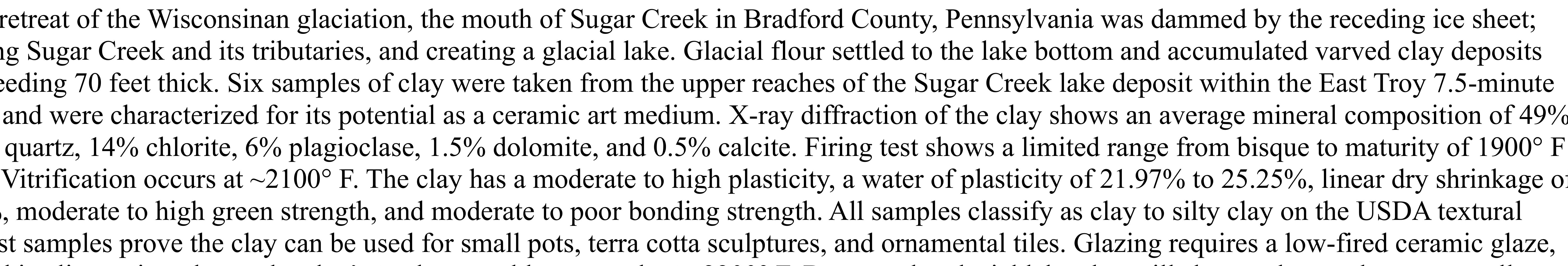
significant aterations ste
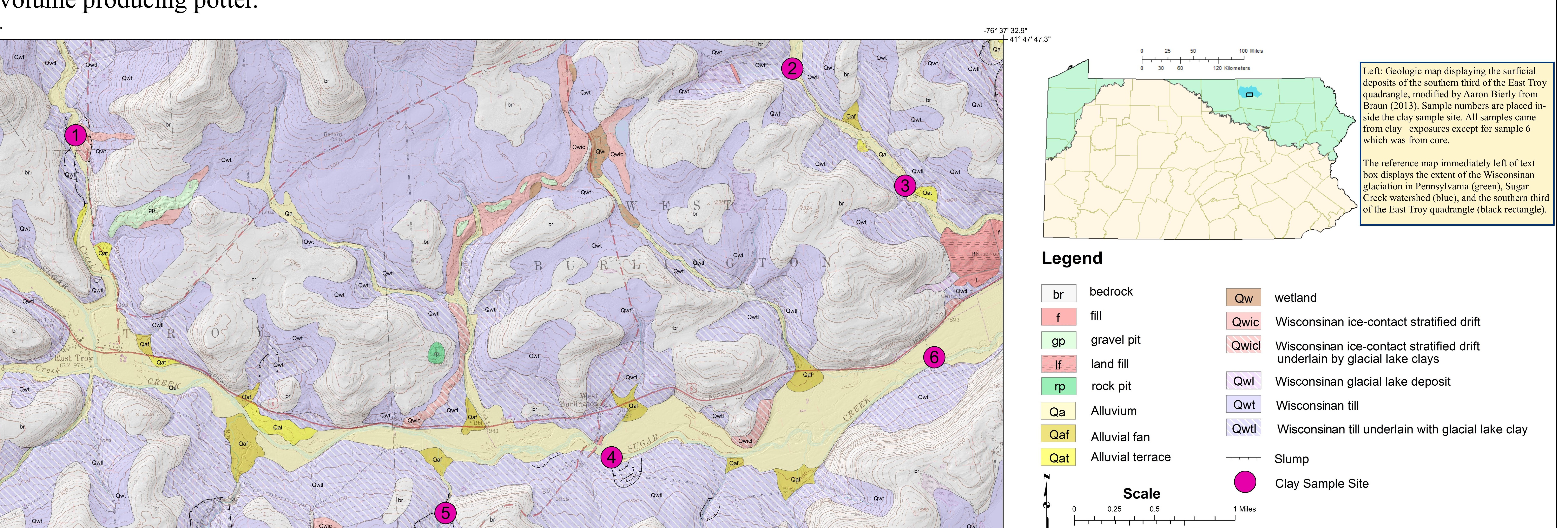

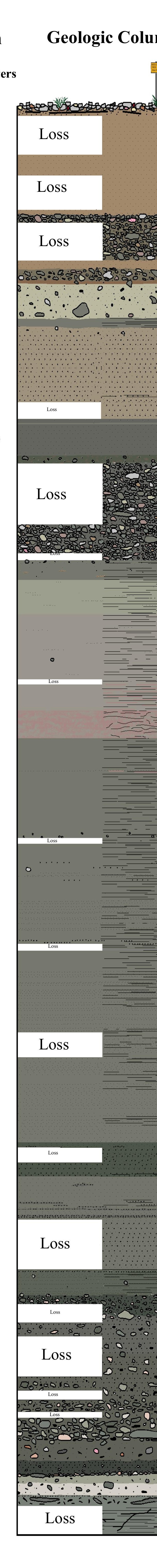
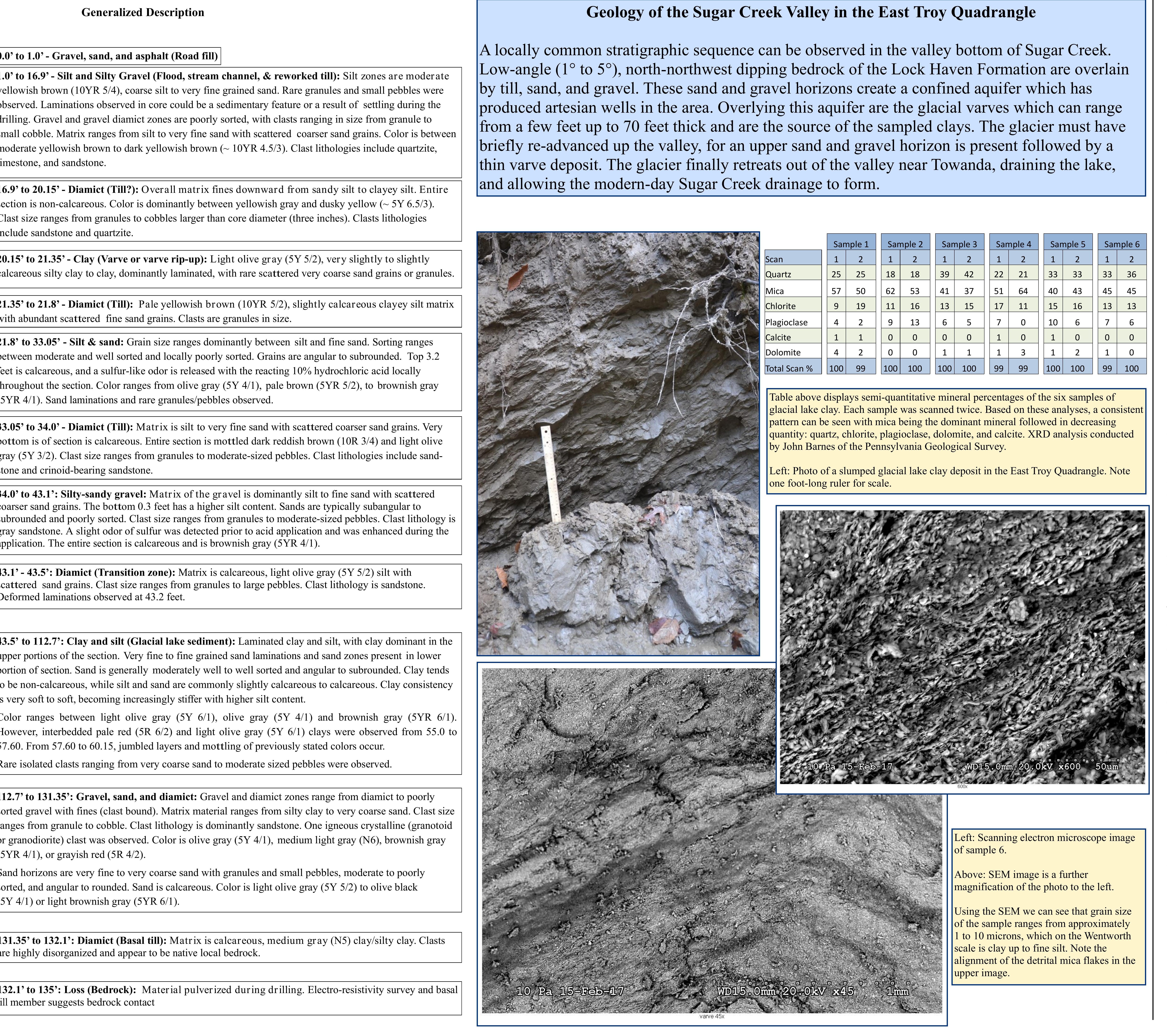

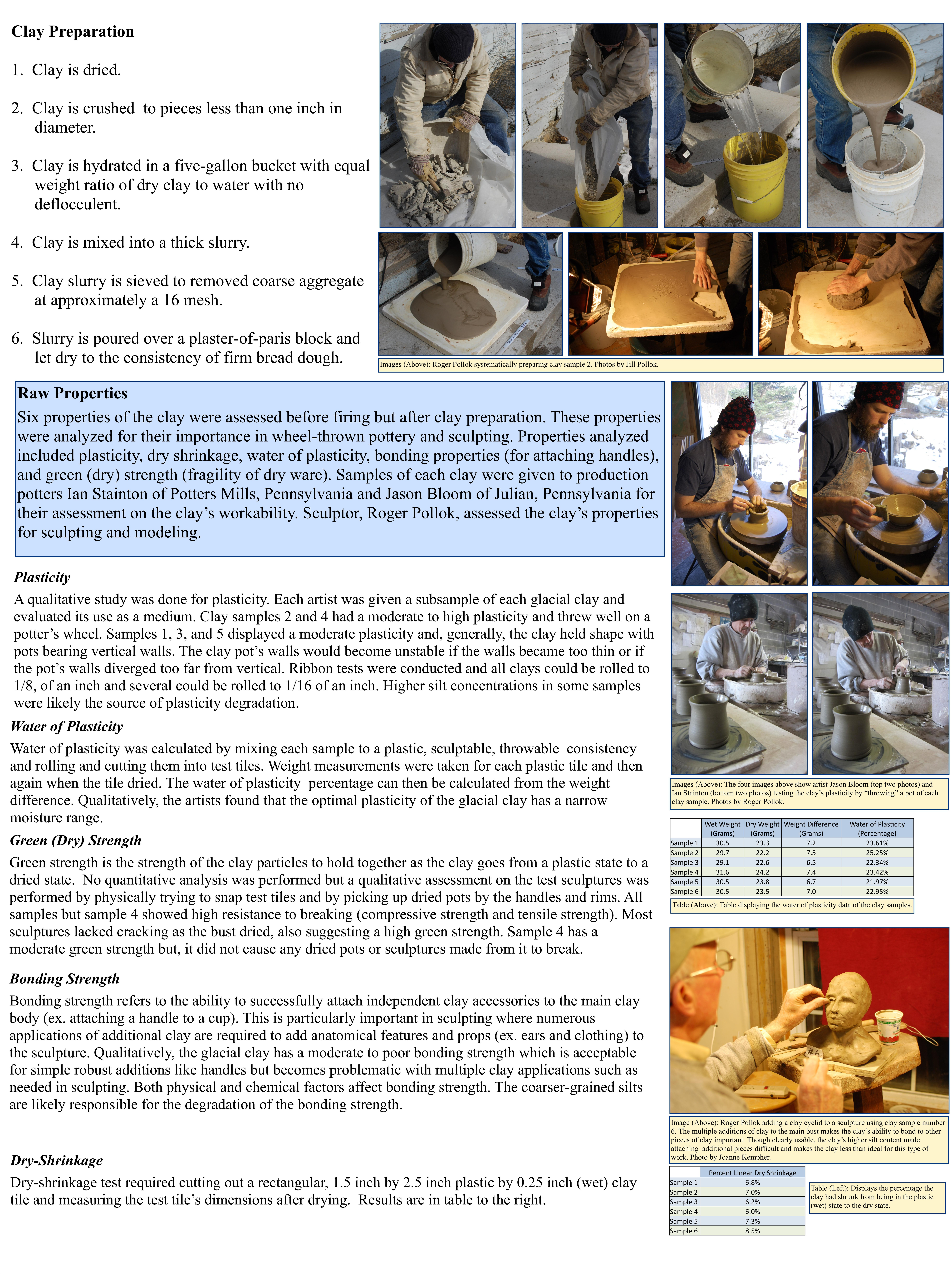

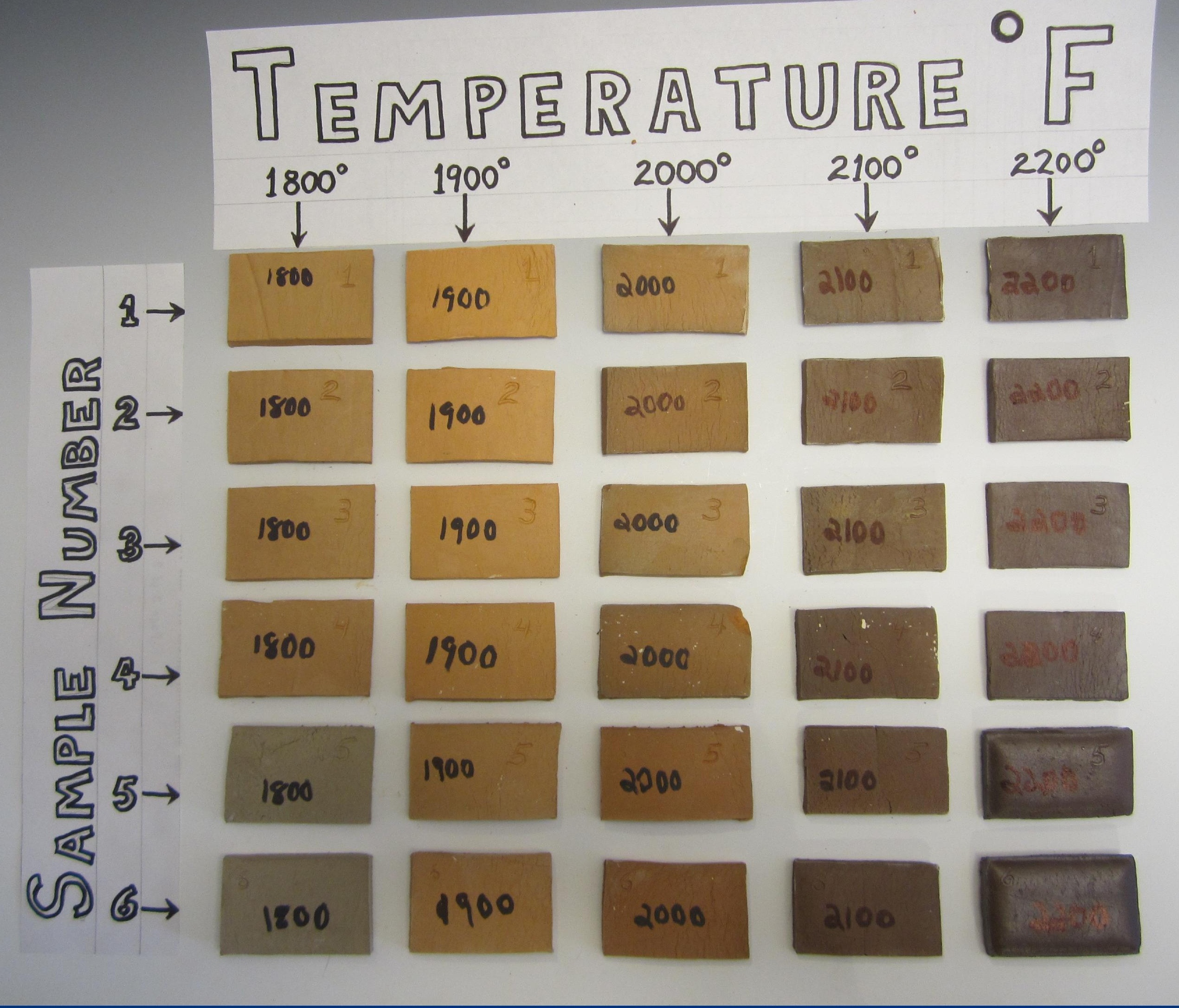
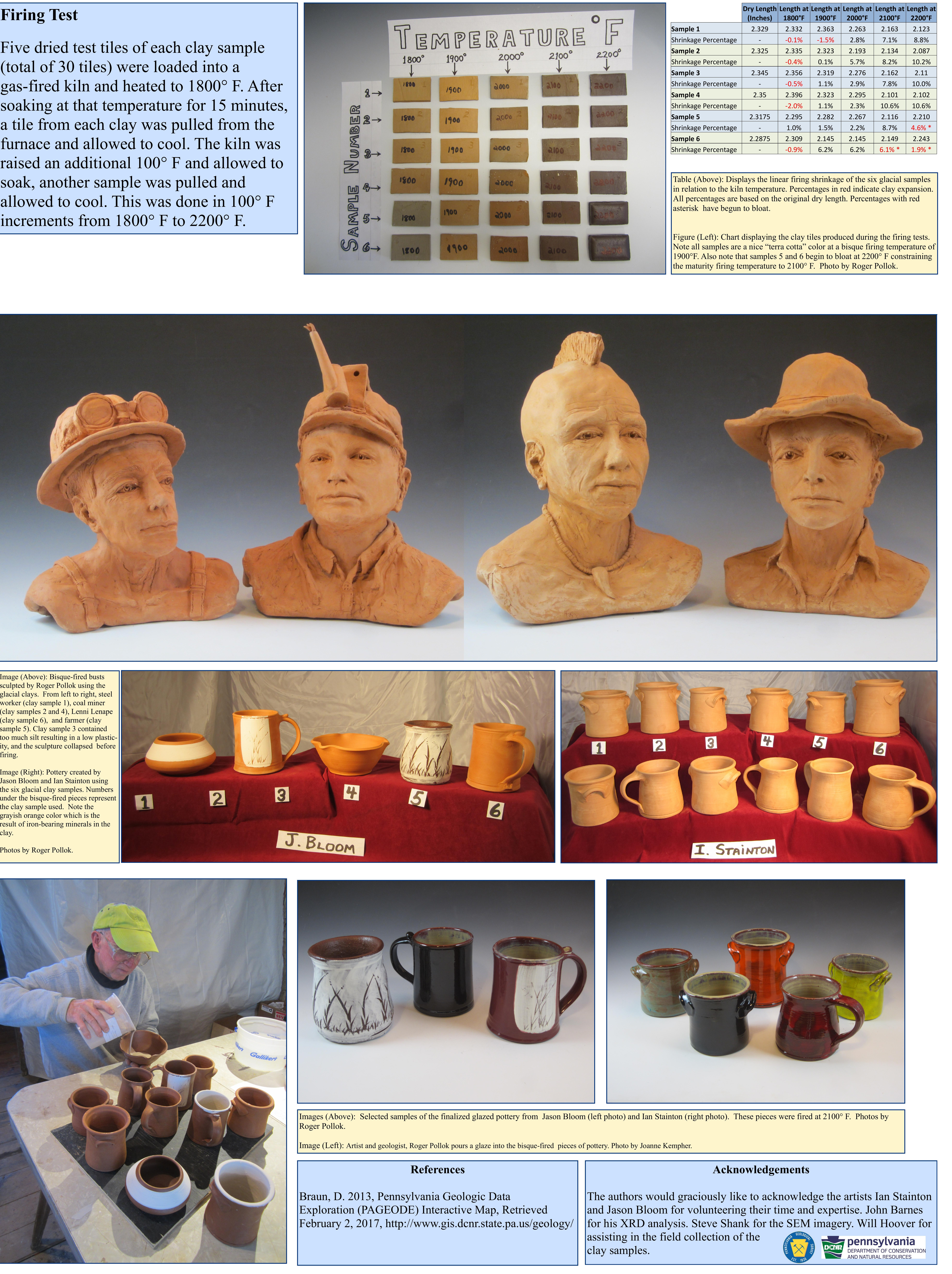